\title{
Perturbations in Conduction in Liquids by Plasma Generated by a Pulsed Laser
}

\author{
Daniela Bertuccelli ${ }^{1,2}$, Héctor Francisco Ranea-Sandoval ${ }^{1,2}$ \\ ${ }^{1}$ Arroyo Seco Physics Institute (IFAS), Faculty of Exact Science, National University of the Central Province of Buenos Aires, Tandil, \\ Argentine \\ ${ }^{2}$ Member of the Scientist Research Career CONICET, Tandil, Argentine
}

Email address:

dbertucc@exa.unicen.edu.ar (D. Bertuccelli)

\section{To cite this article:}

Daniela Bertuccelli, Héctor Francisco Ranea-Sandoval. Perturbations in Conduction in Liquids by Plasma Generated by a Pulsed Laser. American Journal of Modern Physics. Vol. 5, No. 4, 2016, pp. 65-78. doi: 10.11648/j.ajmp.20160504.14

Received: June 9, 2016; Accepted: June 24, 2016; Published: July 18, 2016

\begin{abstract}
The objective of this work is to present the results of measuring the changes in temperature, $T$, oxidation/reduction potential, $O R P$, normal electrode potential, $N E P$, and $p H$ of conducting aqueous mixtures in cells in three situations: with two Copper electrodes, with only one electrode and with none. The situation of two conductors is treated with an external potential and with no applied potential. In all these situations, two identically constructed cells were used. One of them was irradiated with a pulsed high-power laser to produce a plasma. The other cell was not irradiated. Our results are thus presented as difference of the two situations. The results confirm that the plasma produces an increase in the production rate of $H$. It was also obtained some information on the differential precipitation of $C u$ into the solution. The yield of $C u$ dilution and the evolution of the other mentioned parameters confirm previous results and is an indirect proof of an increase of $H$ production.
\end{abstract}

Keywords: Laser, Laser-Generated Plasma, Laser-Induced Breakdown, Electrical Conductivity in Liquids

\section{Introduction}

In 1991, C. A. Sacchi [1] was able to conduct experiments on the generation of plasma within water samples through the laser-induced breakdown, generalizing the results known in gases. In 2001, after conducting experiments in Xe samples $[2,3]$, were performed a series of experiments showing that a conduction cell was severely perturbed if a pulsed plasma was generated [4]. These experiments were followed by further research as can be seen in $[5,6]$.

When the laser generates plasma in the liquid bulk, a brightly lit path is clearly visible through the liquid; it is several centimeters long and with an apparent diameter of about $2 \mathrm{~mm}$ wide. This feature was shown in Figure 2 in reference [5].

It was found that an electric pulse is readily detected forming a circuit with at least a piece of $\mathrm{Cu}$ immersed in the liquid and another electrode. Placing the cell with the electrode surface parallel to and near the plasma region, the peak voltage of this pulse is of the order of $20 \mathrm{mV}$. In $[4,5,6]$ it is hypothesized that this pulse is a result of the double layer destruction formed by the electrified interface, as a result of the forced diffusion of charged ions in the liquid bulk.

The changes observed in the long-term Voltage-Current characteristic curve of an electrolysis process for the same liquid samples, one where the plasma is formed and other in an identical cell without being illuminated by the laser, suggested that there were another variables evolving. The two possible changing variables were the $p H$ and the oxidation/reduction potential. Measurements in [6] confirmed that the evolution is completely different in both cases, so the analysis is extended to other situations and in other experimental conditions.

To establish an approximate theoretical model of the processes by which these effects occur, it was decided to perform a series of experiments detailed in this paper. In order to achieve this, the parameters that vary when the laser irradiates the solution were measured.

The evolution of the $p H$; the ORP and/or NEP suggested to other researchers in the electrochemistry field [7-12] that these can be associated with a change in the production of $\mathrm{H}$ in the corresponding electrode $[13,14,17]$. Since there is no way to measure directly the rate of $\mathrm{H}$ production in the experiment, it was proceeded to measure the changes more 
carefully and systematically, even in cases where no direct electrolysis was undergoing.

In this work it is presented an overview of experiments that led to the establishment of the conduction perturbation phenomenology in cells filled with an electrolyte when a high fluence laser impinges on the liquid bulk; together with new data obtained in further research in the subject.

\section{Experiments Description}

This section is devoted to the description of the specific experiments conducted in each situation with the purpose of unifying the presentation afterwards. As it is shown in the preceding section, several of such experiments were done in the past by us; nevertheless, some of the experiments were repeated here to have new data that supports the main purpose mentioned above. To this end, the following parameters were monitored: temperature $T$, the oxidation / reduction potential $O R P$, and the $p H$ of the electrolyte solution versus the number of laser pulses as a measure of the deposited energy in the liquid mixture, or versus "time" considering that the pulse repetition frequency used was always the same for all the experiments.

Several cells were built made of rectangular glass plates containing, either aqueous solutions of $\mathrm{Na}_{2} \mathrm{SO}_{4}$ in different proportions or bidistilled water. The cells can be adapted to support electrodes made of an electrolytic solid $\mathrm{Cu}$ plate (99.9\% purity) that are mechanically suspended in order to avoid vibrations produced by the shock waves out of the plasma formation region. The approximate size of the plates is: $5 \mathrm{~mm}$ width, $22 \mathrm{~mm}$ height, and $59 \mathrm{~mm}$ length. Besides, the cells admit the positioning of the instruments that monitors the parameters $T, O R P$ and $p H$ in different locations regarding the electrodes. The used cells have a lid that closes them in order to reduce the effects of the atmosphere exposition, although not completely isolated from the atmosphere.

In each experiment, the used cells were two. One is irradiated with a focused $\operatorname{NIR}(\lambda=1.063 \mathrm{~nm}) \mathrm{Nd}^{+3}: Y A G$ $Q-$ Switch laser capable of delivering $450 \mathrm{~mJ}$ pulses at $10 \mathrm{~Hz}$ repetition frequency, and a diameter of approximately $6 \mathrm{~mm}$. However, a variable attenuator was used to control the energy, and a frequency of $2 \mathrm{~Hz}$ in order not to produce permanent oscillations in the liquid or excessive cell heating because of the plasma that is generated in the liquid bulk along the long side of the rectangle. In order to achieve the necessary fluence to obtain plasma, the laser beam was focused by means of an antireflection-coating $20 \mathrm{~cm}$ focal length quartz spherical lens that was used in the references cited above. The other cell is used in the same conditions and in the vicinity of the first, except that the plasma is never formed in it. A control cell is also used to allow the comparison of the plasma effects in the solution.

As mentioned in Section 1, the galvanic pulse is measured in the cases where a metallic piece is immersed in the liquid. This pulse appears regardless of the voltage applied to the $C u$ piece. This pulse evolution was also tracked by means of a probe that is decoupled of the $D C$ current applied (if any) to the cell, and a digital oscilloscope Tektronix, Model 3032B (300MHz bandwidth). In the case when only one electrode is being used, the probe measures the pulse as a voltage between the electrode and the electrolyte, submerging in the liquid a connected $P t$ thin wire to close the circuit.

The $p H$-meter is an Alpha PW-40 from Altronix equipped with an electrode Silver CAP PH5045-3B; 8.2 $\mathrm{mm}$ diameter, approximately, the temperature is measured by a digital thermometer, equipped with a calibrated thermocouple, and the ORP determination is made by an Altronix Alpha PO50TN Gel Sealed Combination, that has inside a $\mathrm{PtCl}$ solution and a $\mathrm{Pt}$ electrode, that achieves a known $\mathrm{Pt} / \mathrm{PtCl}$ equilibrium potential used to have a fixed point for all the experiments.

The evolution of the parameters of the tests is analyzed comparing the results of uncovered cells and the aforementioned covered cells. In order to compare some of the results, the ambient temperature was registered for all the described measurements.

The Figure 1a is a schematic of the experiment showing the relative positions of all the used probes to register the data and one of the positions where the plasma is generated. This situation corresponds to the case 1 , but is similar in all the other situations (Figure $1 \mathrm{~b} ; 1 \mathrm{c} ; 1 \mathrm{~d}$ ). The NEP is measured placing a standard $H$ electrode as close as possible to the surface of each $\mathrm{Cu}$ piece. A picture of the laser generated plasma was already published in 2001 and in 2010. The plasma looks like a cylinder which ends are seemingly cones and is a bright blue-white glowing region which is approximately $40 \mathrm{~mm}$ long and appears to be less than $2 \mathrm{~mm}$ in diameter in photographs (see, for example [5]).

The used solutions were all $0.9 \times 10^{-3} \mathrm{M}$, approximately, of $\mathrm{Na}_{2} \mathrm{SO}_{4}$ in bidistilled water, except when noted.

The experimental results for three situations are here presented, as follows (always considering both, the cell under the laser irradiation to generate plasma and the twin cell):

1. The cell is filled with a conductive solution but without $\mathrm{Cu}$ pieces.

In this set of experiments, the aqueous solution fills the cell and the measurements registered, as usual, were the temperature, $T$, the $p H$, and the ORP. The comparison is between the irradiated cell and the twin cell. Another comparison is between the pairs of uncovered small cells and the pair of covered large cells.

2. The cell is filled with a conductive solution but with only one $C u$ piece.

This situation describes the case when a single $\mathrm{Cu}$ plate is immersed in the cells. In this case, to the instruments used in the preceding experiments, a very thin $P t$ electrode was added as a reference potential, in order to determine the electric pulse appearing in the circuit, with or without an external battery. In these cases, the peak of the pulse was registered changing both, the distance $D$, from the laserplasma to the electrode surface, and the distance $d$ between the $P t$ electrode to the $C u$ plate to detect the perturbation of the conduction. Also $T, p H, O R P$ and/or $N E P$, were monitored according to the case under study.

The pulse peak dependence that appears when the 
electrodes are immersed in the solution, with the energy of the impinging laser and other external parameters is investigated in [2] and the analysis is not repeated here.

3. The cell is filled with a conductive solution with two $C u$ pieces placed with some distance. It is necessary to distinguish the case where an external battery produces electrolysis in the system.

In the case of two immersed plates, both were placed at a distance $d$ and the plasma is formed at a distance $D$ from one of them.

The measures were taken with and without a battery producing the electrolysis.

In all cases, it is compared the evolution of the parameters described in cells of different volumes of solution. There is a pair of $21 \mathrm{ml}$ cells and another pair of $80 \mathrm{ml}$ cells which are covered to avoid somehow the atmosphere exposure. Except for the experiments with electrolysis described below, all the performed analysis were repeated in both type of cells.
The use of a control cell, not subjected to the breakdown perturbations on the conduction properties, allows to perform a difference in the analysis for the important parameters. In the case of external circuit conduction, it is possible to make another difference, this time between the conducting cell with plasma perturbing the conduction, and a control cell where the conduction is avoided. Since in these cases a twin cell is always used as control, it is possible to speak of a second difference in the displayed parameter. Summarizing, a first difference would represent the difference of the chosen parameter for an irradiated cell compared to the control cell, while a second difference would stand for the difference between the parameter of a cell in conduction state, compared to the twin cell, and in turn this is compared to the parameter in a cell in conduction with no laser irradiation with respect to the twin control cell that does not conduct current. This would discard other mechanisms present in the electrolysis that could eventually change the conduction characteristics.

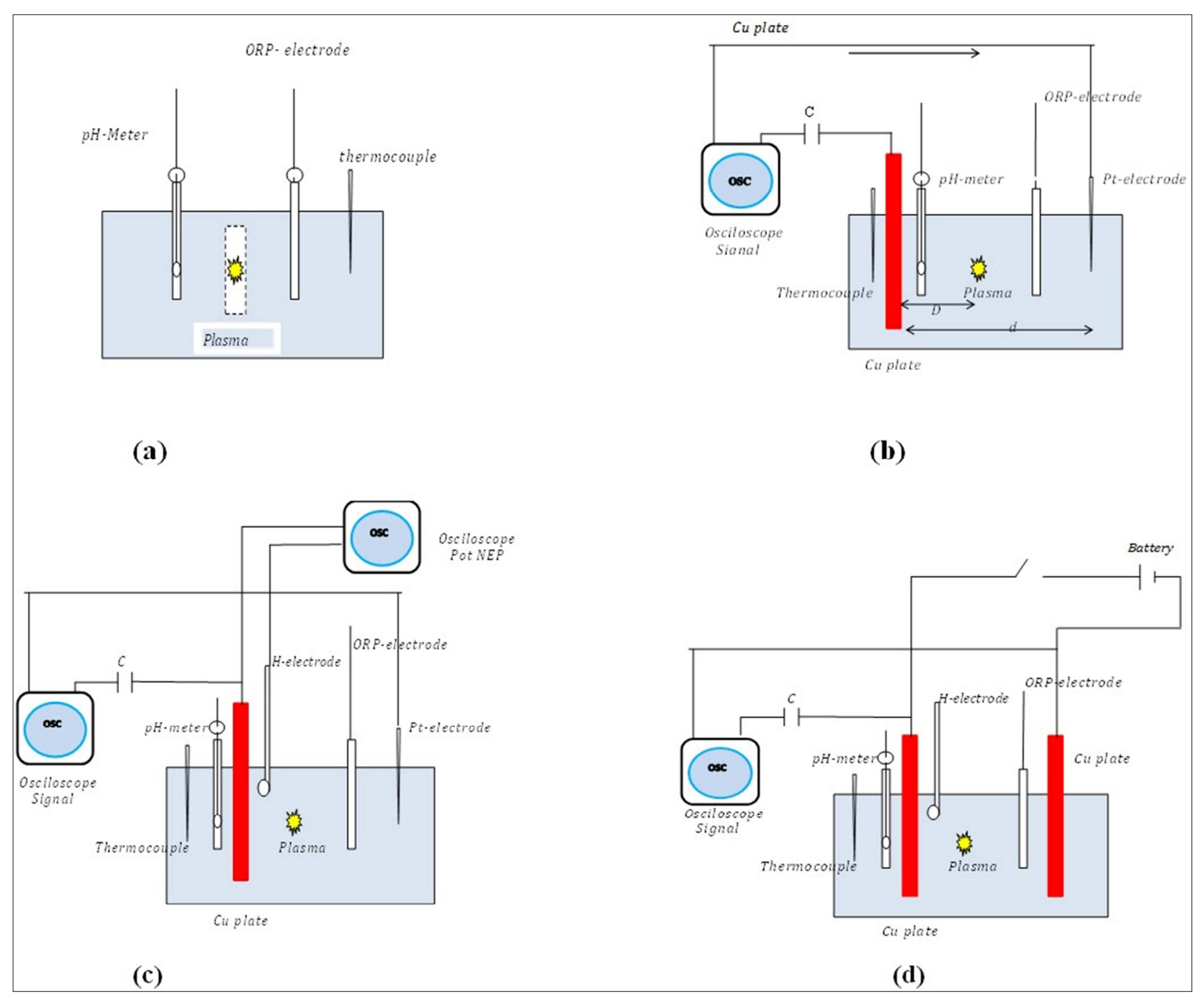

Figure 1. Scheme of irradiated cell and meters location for: (a) case 1: without submerged metallic surfaces; (b) case 2: with a large size and flat copper plate, and a counter-electrode of Platinum wire; (c) case 2: used scheme for the measurement of electrodes standard potentials and (d) case 3: with two large size and planar Copper plates. D: distance from Cu plate to the plasma. d: distance from Cu plate to the counter-Pt electrode.

\section{Results, Analysis and Discussion}

It is described the main results for each set of experiments in the situations described above.
The temperature in the cell undergoes a change due to heat deposited in the liquid, which is always similar to the one displayed in Figure 2 corresponding to the case of the cell without $\mathrm{Cu}$ plates immersed in the liquid, with only minor differences for the other cases under study. 


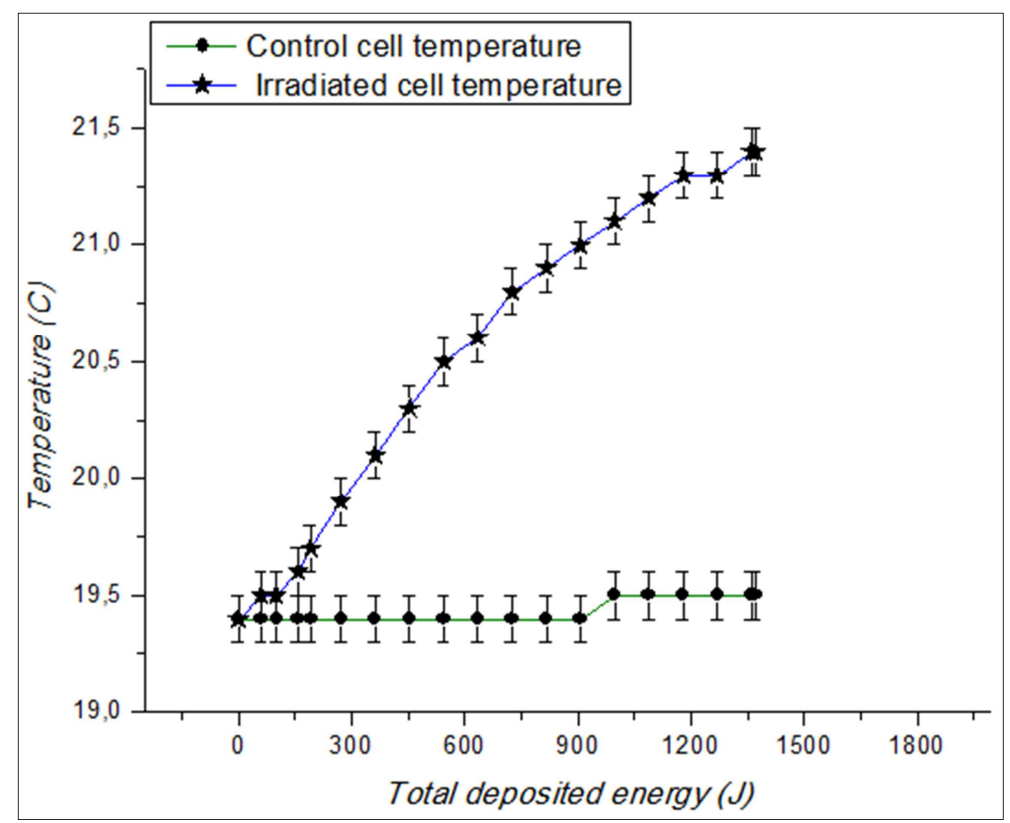

Figure 2. Temperature of radiated solution versus the total deposited energy; and temperature of non-radiated solution. Cells without metal submerged surface.

\subsection{Cell without Cu Plates}

The used cells were without the plates; hence the only elements inside them were the instruments for temperature, $p H$, and $O R P$ determination.

The measured $p H$ evolution versus the total delivered energy to the system (at an energy per pulse of $378 \mathrm{~mJ}$ ) is shown in Figure 3a for the cell where the plasma is formed (hollow stars), and for the control cell (hollow circles). After $250 \mathrm{~J}$ (which corresponds approximately to 5 minutes of laser operation at a repetition frequency of $2 p p s$ ) the two $p H$ curves begin to separate: the control cell becoming more acid and the cell under the action of the laser, becoming more basic. The Figure $3 \mathrm{~b}$ displays both differences, the $\Delta p H=$ $p H_{\text {laser }}-p H_{\text {control }}$ that is, the difference in the $p H$ of the cell with the plasma respect the control cell. The cells used in this experiment are not covered, so the acidification is probably due to the natural $\mathrm{CO}_{2}$ content.

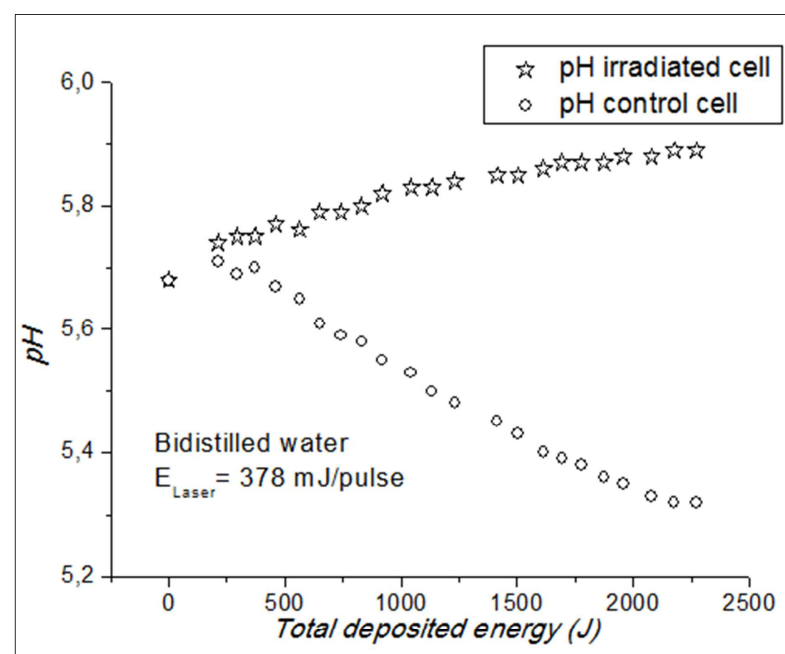

(a)

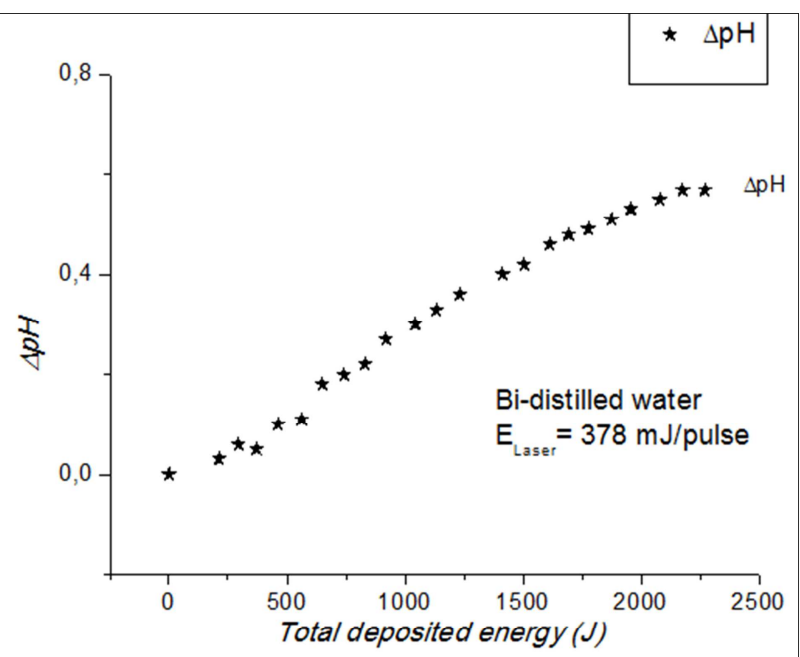

(b)

Figure 3. (a) pH versus the total deposited energy for the two cells. (b) $\Delta p H$ versus the total deposited energy. Example of application of the measurement method for bi-distilled water as electrolyte. Uncovered small cell. Laser energy is $378 \mathrm{~mJ}$ per pulse.

For covered cells, the curves are shown in Figure 4. The control cell keeps the $p H$ much more levelled than the uncovered one, while the one receiving the laser action (which is also covered) increases its value in a consistent manner with the results of Figure $3 \mathrm{a}$. 


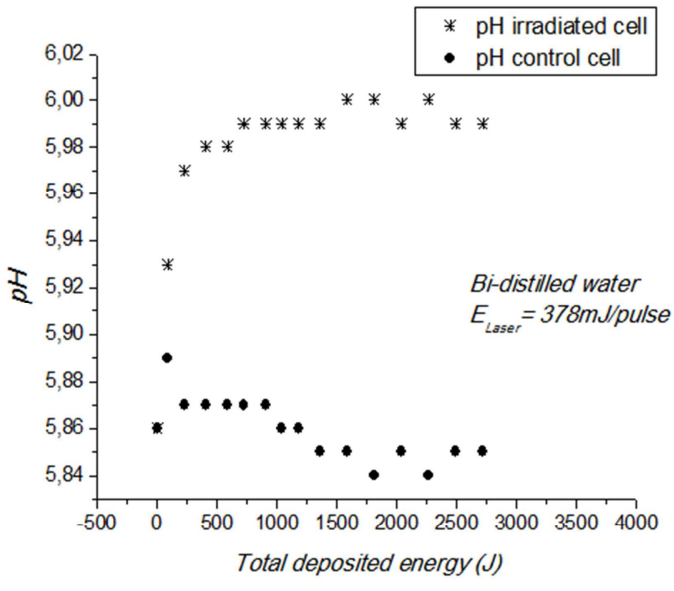

(a)

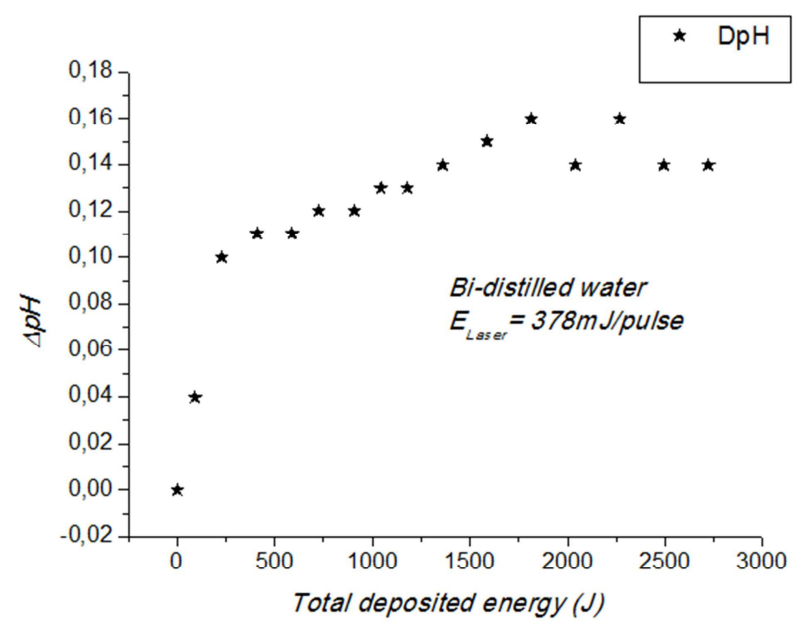

(b)

Figure 4. (a) $p H$ versus the total deposited energy for the two cells. (b) $\Delta p H$ versus the total deposited energy. Example of application of the measurement method for bi-distilled water as electrolyte. Covered cells. Laser energy is $378 \mathrm{~mJ} / \mathrm{pulse}$.

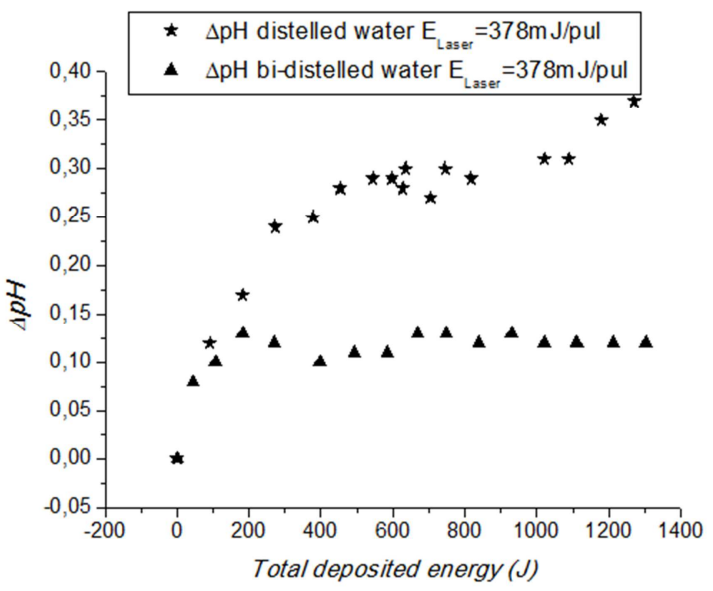

(a)

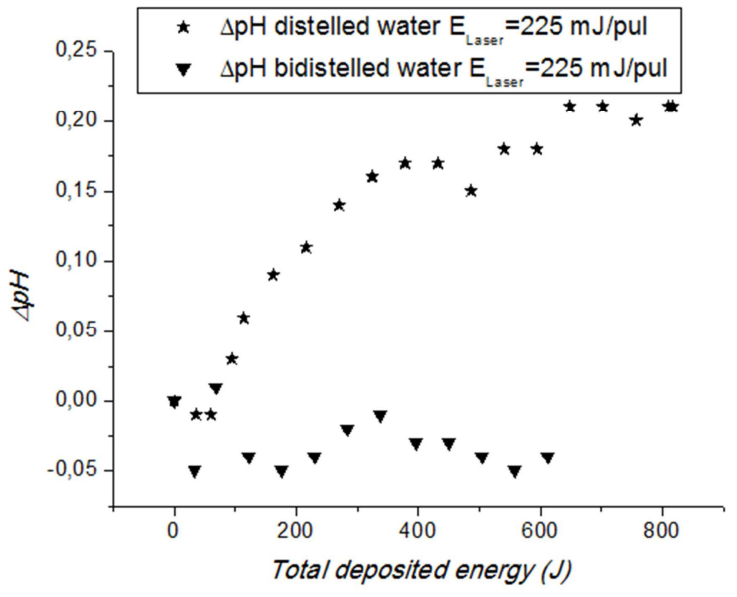

(b)

Figure 5. $\Delta p H$ versus the total deposited energy. Comparison between bi-distilled water and distilled water, as the cell solution, for two different laser energies. (a) $E_{L}=378 \mathrm{~mJ}$ per pulse and (b) $E_{L}=225 \mathrm{~mJ}$ per pulse. Uncovered small cell.

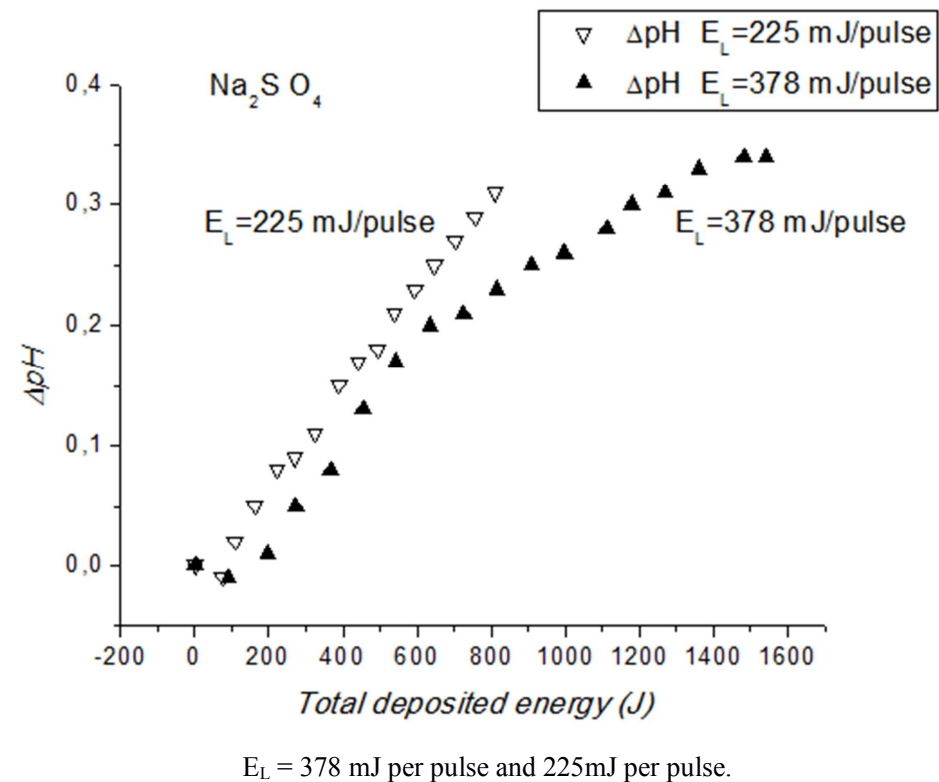

Figure 6. Comparison of $\Delta p H$ versus the total deposited energy in cells with an aqueous Sodium Sulfate solution, for two different laser energies. 


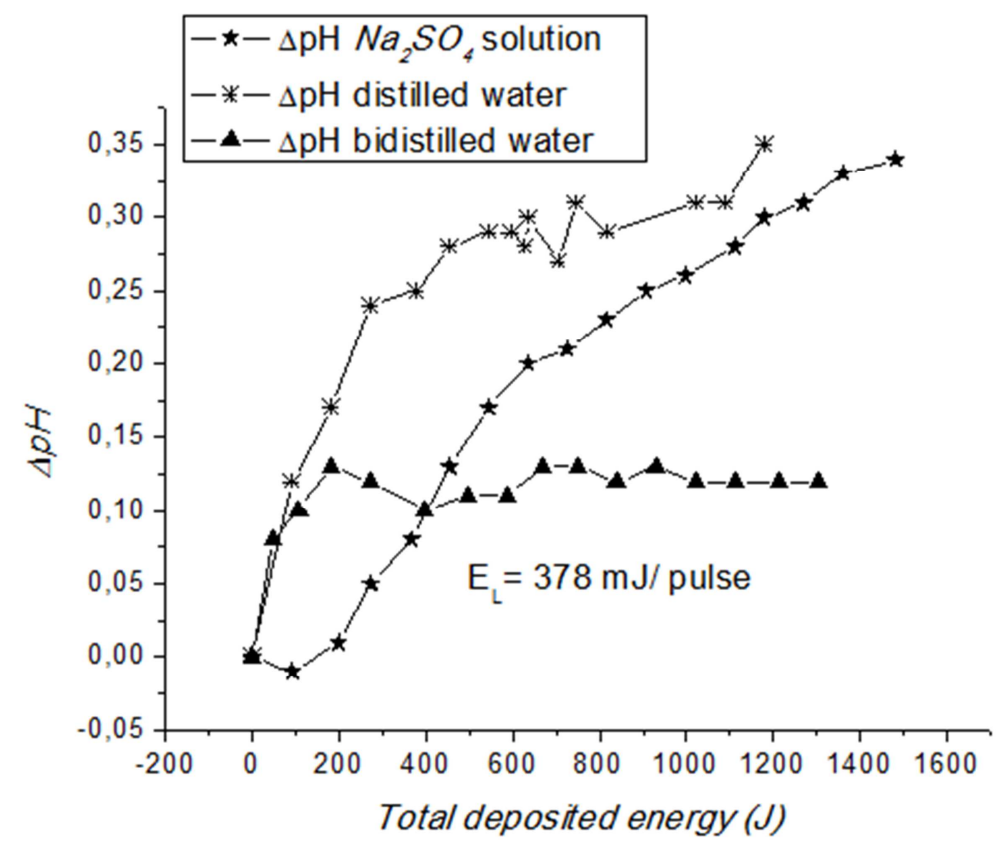

Figure 7. Comparison of $\triangle p H$ versus the total deposited energy in cells with an aqueous Sodium Sulfate solution ( $\star$ solid star), for distilled water (* asterisk) and for bi-distilled water ( $\boldsymbol{\Lambda}$ solid triangle). $E_{L}=378 \mathrm{~mJ}$ per pulse. Uncovered small cell.

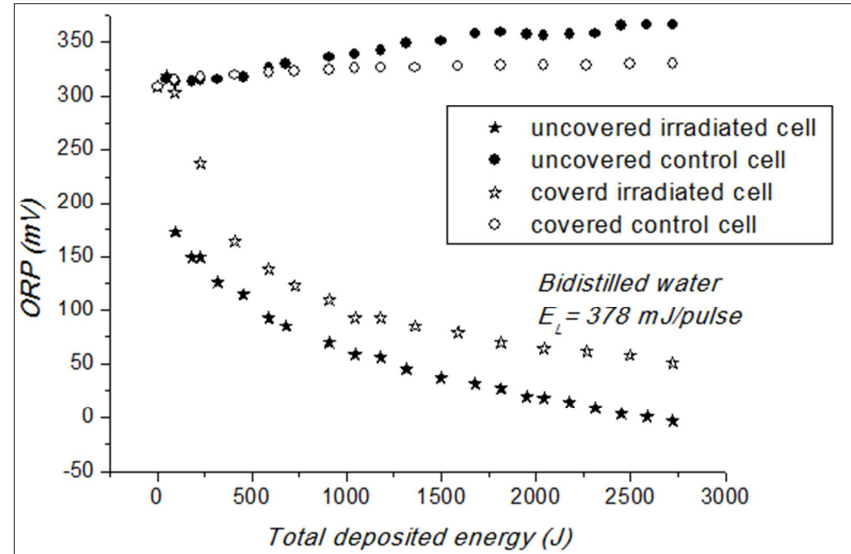

(a)

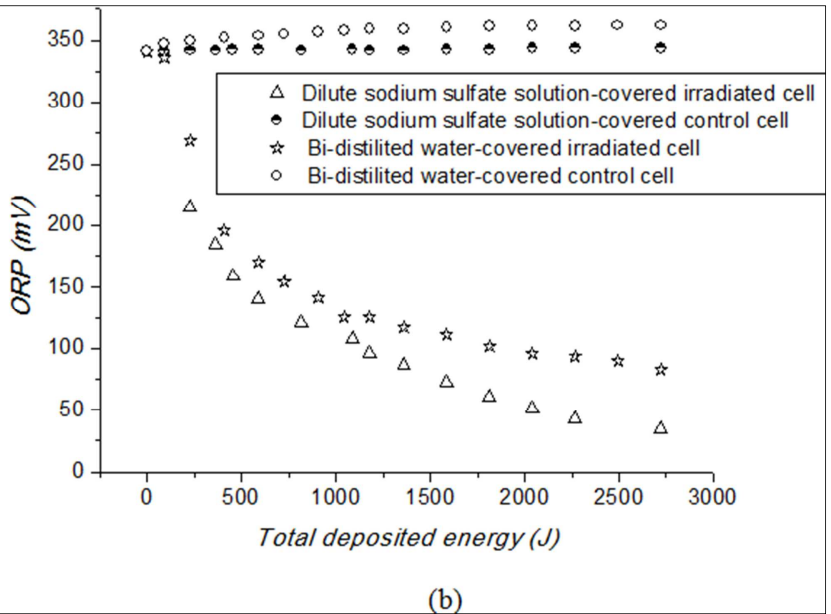

(b)

Figure 8. (a) Comparison of ORP evolution, versus the total deposited energy in the control cell and the irradiated cell, for the two pairs of covered cells (open symbols $\circ, \downarrow)$ ) and uncovered cells (solid symbols $\bullet$, 丸) for a bi-distilled water solution. EL = $378 \mathrm{~mJ}$ per pulse. (b) Comparison of ORP evolution, versus the total deposited energy in the control cell and the irradiated covered cell (open symbol $\circ$, is, $\Delta, 0)$ for a bi-distilled water solution and for a dilute sodium sulfate solution. $E L=378 \mathrm{~mJ}$ per pulse.

The analysis for different water purification state was also performed, namely distilled and bidistilled water, for two different energy values per pulse. In Figures $5 \mathrm{a}$ and $5 \mathrm{~b}$ it is shown that for higher energy, the $\Delta p H$ is higher.

In Figure 6 it is shown the same parameter evolution for a $\mathrm{Na}_{2} \mathrm{SO}_{4}$ liquid solution of $0.9 \times 10^{-3} \mathrm{M}$ approximately, for two energy per pulse: $225 \mathrm{~mJ}$ and $378 \mathrm{~mJ}$. The interesting feature about these results is that the $\Delta p H$ curve for the higher energy is always below the curve corresponding to lower energy, indicating that some of the channels in the plasma chemistry are more efficient in reducing the $p H$ for higher energies. To long expositions, the electrolyte is probably consumed, and the evolution comes to a saturation region.

The change in the $p H$ solution is shown in Figure 7 , for laser pulse energy of $378 \mathrm{~mJ}$ for bidistilled water, distilled water and the $\mathrm{Na}_{2} \mathrm{SO}_{4}$ solution.

In Figure $8 \mathrm{a}$ and $8 \mathrm{~b}$ it is presented the $O R P$ evolution in different variations of the cells without $C u$ plates. Figure $8 \mathrm{a}$ plots the ORP for both cells cases, the control and the exposed to the laser, where in one case both are open to the atmosphere (filled symbols), and in the other are close by the lid (open symbols). While the ORP in the uncovered control cell climbs up about $23 \%$, the $O R P$ in the covered control cell hardly presents a measurable change. But the ORP of both irradiated cells decrease simultaneously $100 \%$ of its initial value, but maintains a $30 \%$ of distance from one to the other. This decrease of $100 \%$ indicates that the medium becomes more reductant. 
Figure $8 \mathrm{~b}$ is similar to the previous one, except that compares the ORP for cells containing bidistilled water and the aforementioned $\mathrm{Na}_{2} \mathrm{SO}_{4}$ solution.

The drop in the ORP is consistent with the increase in $p H$ indicating that the solution is becoming more reductant. This is the case in all the studied solutions and with the described conditions.

\subsection{Cell with One Cu Plate}

In this case one $\mathrm{Cu}$ piece was immersed in twin and irradiated cells solutions and the parameters were measured in several conditions. In addition to the measurements of these parameters, it is possible to introduce a thin $P t$ wire and use it as the counter-electrode and determine the value of the galvanic pulse that appears as a result of the laser generated plasma.

Temperature measurements are not detailed, since they bring similar results to the presented above.

Figure 9 shows an example of the galvanic pulse that is possible to register when the laser generates plasma in the liquid bulk. The example is taken from data gathered at a cell filled with the same solution of $\mathrm{Na}_{2} \mathrm{SO}_{4}$ as before, using a laser pulse energy of $378 \mathrm{~mJ}$ and has a peak of approximately $2 \mathrm{mV}$ and is the result of an averaging 32 pulses. The plasma in this example was formed at $D=2 \mathrm{~mm}$ away from the $\mathrm{Cu}$ piece. The total pulse duration, measured until the perturbation disappears is $15 \mathrm{~ms}$, being its tail very long. Similar pulses were detected when the cells were filled with distilled or bidistilled water, although they had lower peak values.

The intensity pulse dependence was registered with the laser energy, which led to Figure 10 plot. In this case, the distance between the $P t$ electrode and the $C u$ plate was $6 \mathrm{~mm}$ and the plasma was formed $5 \mathrm{~mm}$ away from the plate.

The galvanic pulse was also compared for different distance from the plate to the plasma and the results were previously reported in the cited references [6]. The linearity of the intensity pulse dependence is good, but the striking feature is the change in the slope for different distances to the plasma and the inversion for distances greater than $4 \mathrm{~mm}$. These features are evident in the published data in the cited references, also, where it was parameterized the galvanic pulse peak with the laser pulse energy and plot it against the distance between the plasma and the $C u$ plate. It is evident from the results reported in that publication, that a maximum is achieved near the mentioned $D=4 \mathrm{~mm}$ for this arrangement, and is independent of the laser pulse energy $[5,6]$.

The relation between the pulse peak and the distance $D$ is also not linear. This is represented in Figure 11. In fact, it displays a minimum at a distance of the order of $D=1 \mathrm{~mm}$. The Pt counter-electrode is situated at $d=6 \mathrm{~mm}$.

It was also measured the change of the $p H$ solution for several plasma locations relative to the $C u$ plate $(D)$, showed in Figure 12, for a solution of $\mathrm{Na}_{2} \mathrm{SO}_{4}$, so it can be correlated to the galvanic pulse in the electrolyte. This change is taken between the cell exposed to the laser and the control cell. The $\mathrm{pH}$ variation is greater the closer the plasma is from the electrode. The maximum $\mathrm{pH}$ variation corresponds to the highest intensity pulse. This change becomes smaller for larger $D$.

The relation between the pulse peak and the distance $D$ is also not linear. This is represented in Figure 11. In fact, it displays a minimum at a distance of the order of $D=1 \mathrm{~mm}$. The Pt counter-electrode is situated at $d=6 \mathrm{~mm}$.

It was also measured the change of the $p H$ solution for several plasma locations relative to the $C u$ plate $(D)$, showed in Figure 12, for a solution of $\mathrm{Na}_{2} \mathrm{SO}_{4}$, so it can be correlated to the galvanic pulse in the electrolyte. This change is taken between the cell exposed to the laser and the control cell. The $\mathrm{pH}$ variation is greater the closer the plasma is from the electrode. The maximum $\mathrm{pH}$ variation corresponds to the highest intensity pulse. This change becomes smaller for larger $D$.

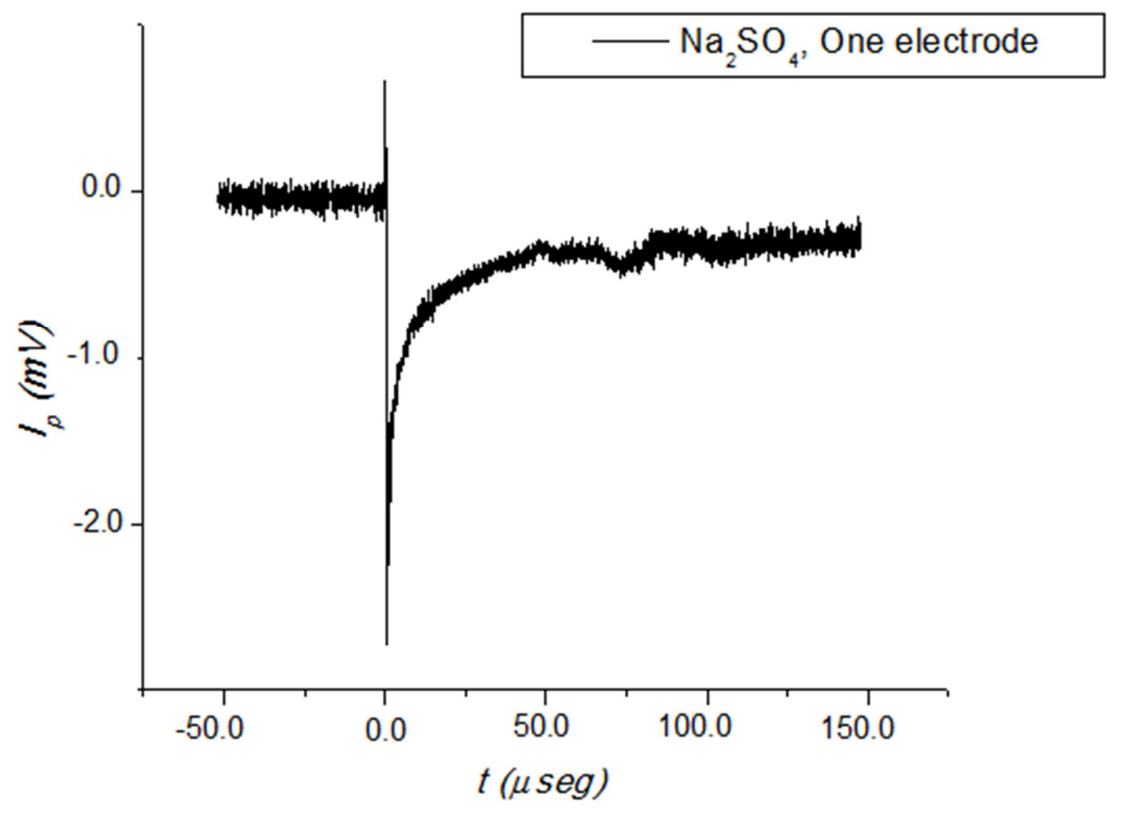

Figure 9. The galvanic pulse obtained when the plasma is formed in a dilute sodium sulfate solution in cells with a Cu plate. $E_{L}=378 m J / p u l s e$. 


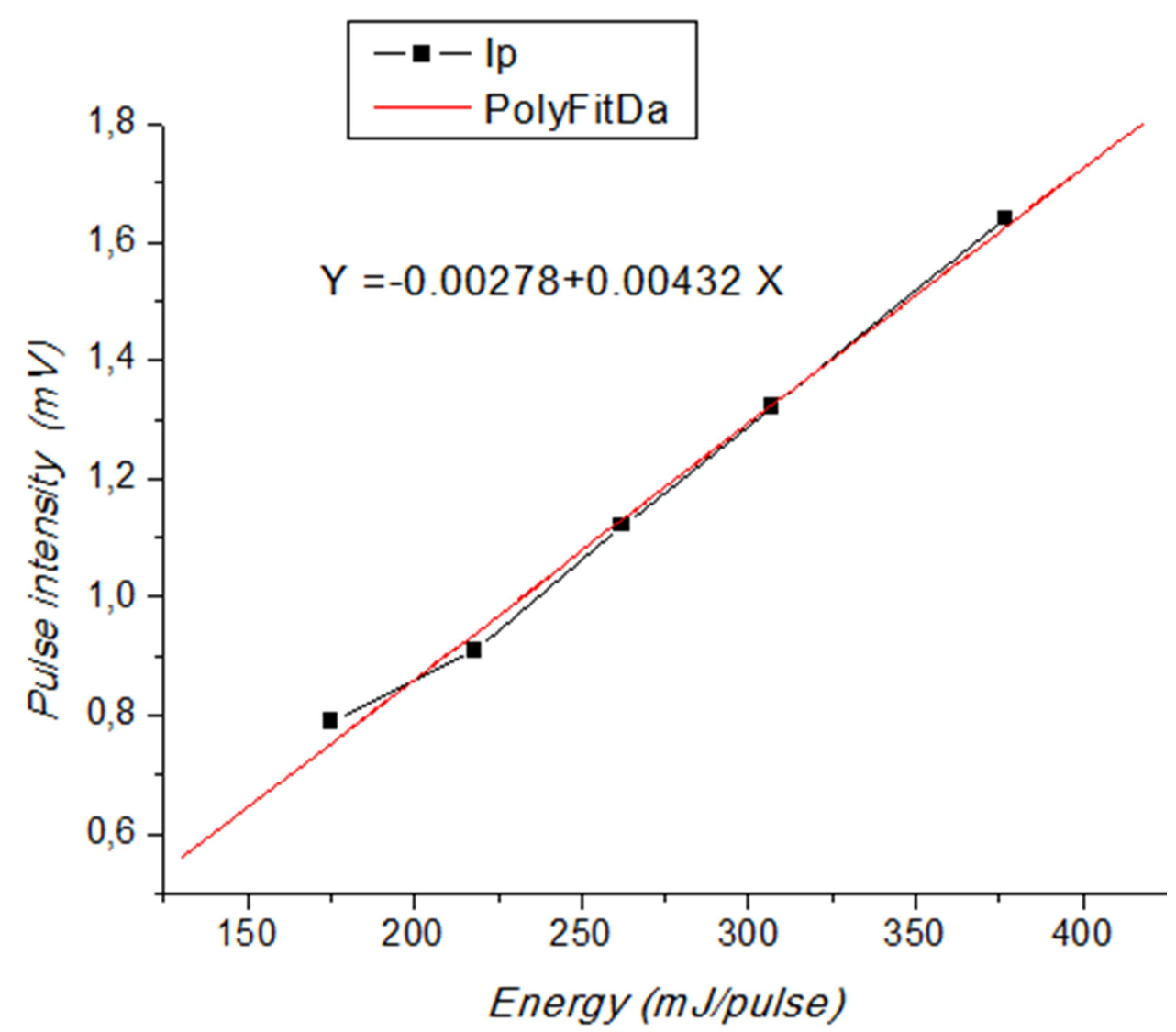

Figure 10. Graphic of galvanic pulse intensity versus the laser energy in cells with a Cu plate. The distance between the Pt electrode and the Cu plate was $6 \mathrm{~mm}$. The distance between the formed plasma and Cu plate was $5 \mathrm{~mm} . E_{L}=378 \mathrm{~mJ} /$ pulse.

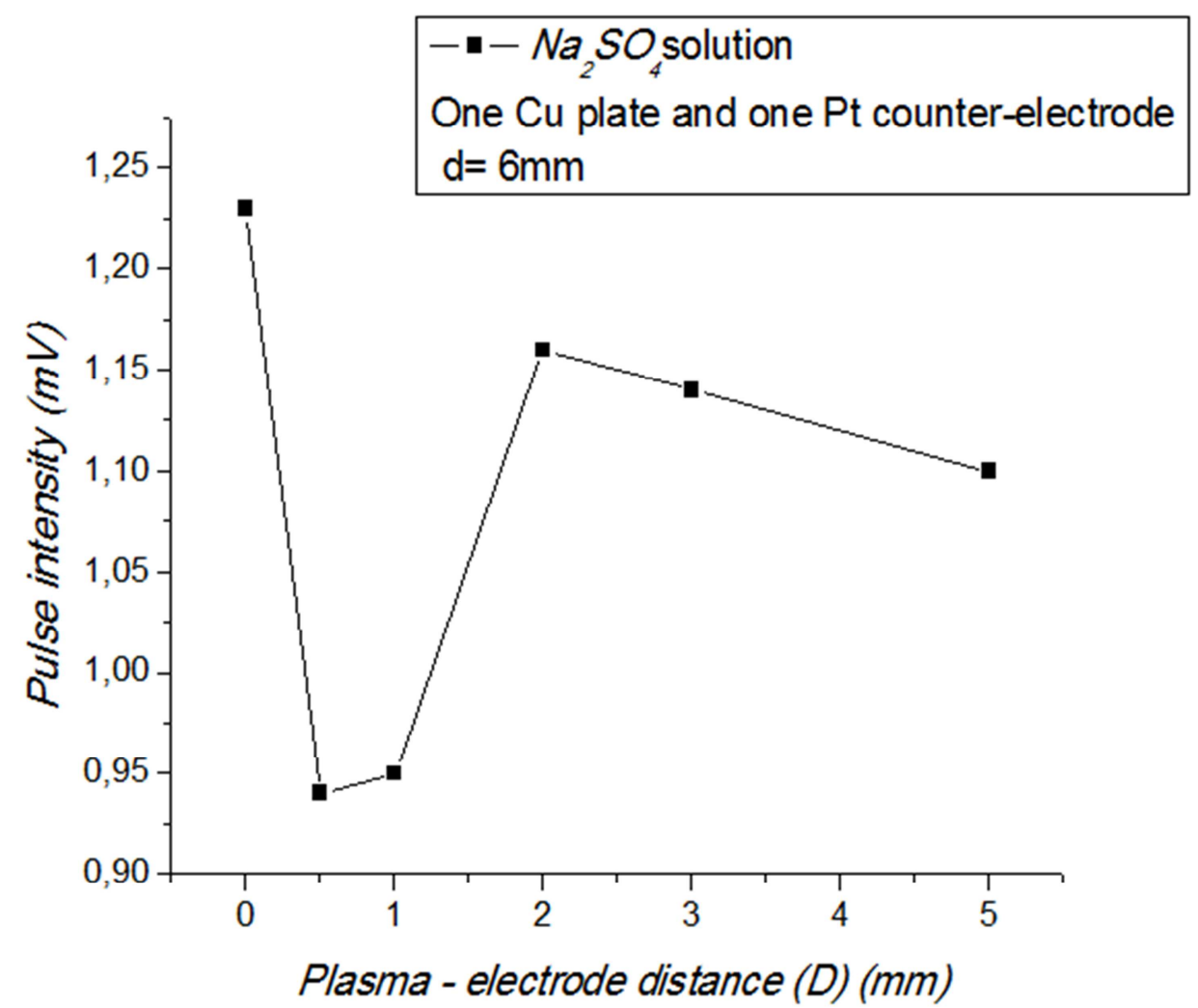

Figure 11. Graphic of galvanic pulse intensity versus distance between the plasma and the Cu plate (D). The Distance between the Pt electrode and the Cu plate was $6 \mathrm{~mm} . E_{L}=378 \mathrm{~mJ} /$ pulse. 


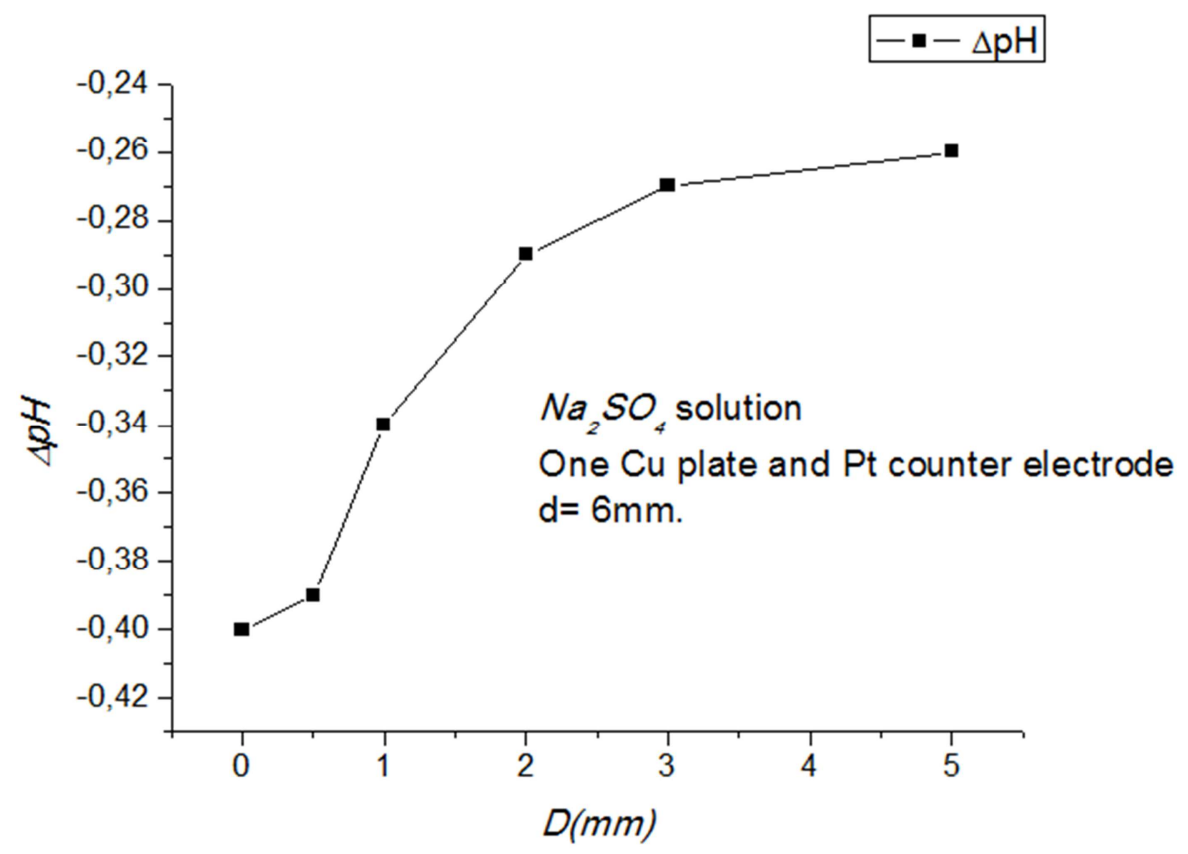

Figure 12. Graphic of $\triangle p H$ versus $D$, (distance between the formed plasma and the Cu plate). Electrolyte of diluted sodium sulfate solution. The Distance between the Pt electrode and the Cu plate was $6 \mathrm{~mm} . E_{L}=378 \mathrm{~mJ} /$ pulse.

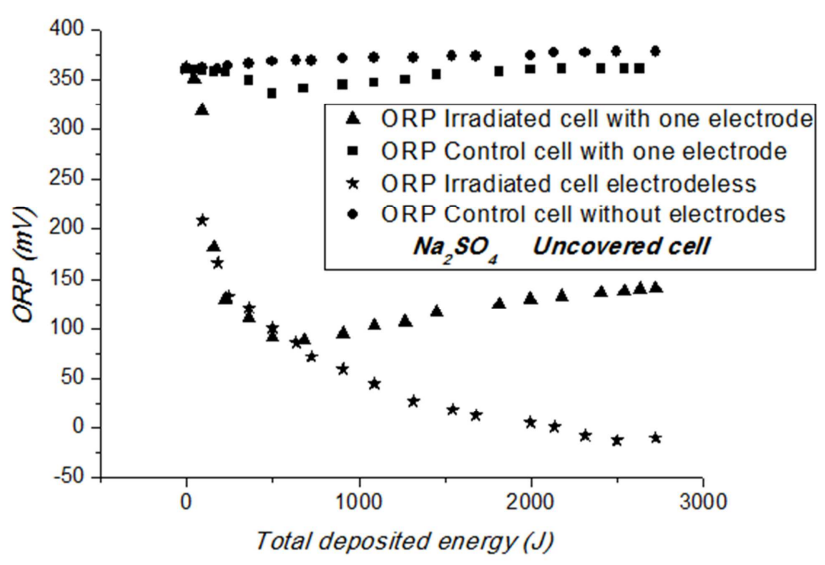

(a)

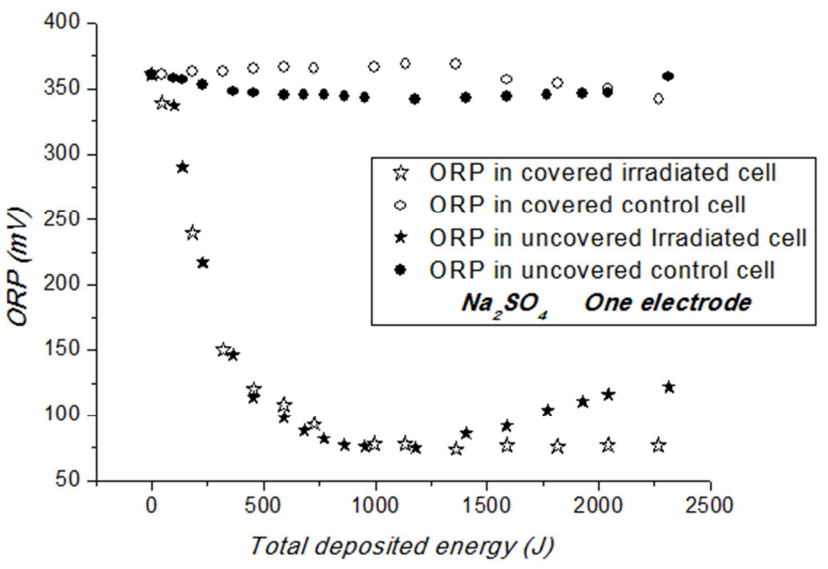

(b)

Figure 13. (a) Comparison of ORP evolution versus the total deposited energy, in the control cell and the irradiated cell; for non-Cu plate cell and Cu plate cell. Uncovered small cells. Dilute sodium sulfate solution. $E L=378 \mathrm{~mJ}$ per pulse. (b) Comparison of ORP evolution versus the total deposited energy, in the control cell and the irradiated cell with a Cu plate; for uncovered cell and covered cells. Dilute sodium sulfate solution. EL $=378 \mathrm{~mJ}$ per pulse.

Finally, it is shown the comparison for the ORP evolution for cells filled with a $\mathrm{Na}_{2} \mathrm{SO}_{4}$ solution, with a $\mathrm{Cu}$ piece in it and without it, as usual, compared with the respective control cell (not irradiated). For the $O R P$, it was recorded its values to make the Figure 13a where it is plot against the total delivered energy to the liquid. The control cell is represented by filled symbol and remains approximately invariant during the experiment, while the $O R P$ of the exposed cell to the laser drops. This drop in the cell without electrodes is remarkable, since this potential may arrive to negative values. In the case of one immersed $C u$ plate, the ORP achieves an equilibrium value lower than the initial potential but keeping its sign.

Figure 13b, shows another example of this results taken in covered cells, instead. The general behavior is that the cell with a $\mathrm{Cu}$ plate immersed, tends to increase the ORP as time proceeds, after it has reached very small, in cases almost null potential (taking even negative values in some cases). The effect of the metallic piece in the control cell is more clearly discernible in the closed cell case.

In order to interpret correctly the state of the solution before and after the exposition to the laser generated plasma it was also performed a series of measurements of the normal electrode potential by means of an $H$ probe. In Figures $14 \mathrm{a}$ and $14 \mathrm{~b}$, it is plot the $N E P$ and the $p H$ versus the total deposited energy in the cell exposed to the laser. With this two plots, Figure $14 \mathrm{c}$ was constructed, representing the $N E P$ change as the $p H$ changes which shall allow an interpretation by means of comparison to the Pourbaix diagram [7-9], that represents the possible equilibrium phases of an aqueous electrochemical 
system such as ours. With these diagrams it is possible infer what kind of elements are dissolved in the solution.

In Figure 15 the Pourbaix diagram is represented for several $D$ values for aqueous solutions in cells exposed to the laser and, for comparison, the same diagram for the control cell for bidistilled water and $\mathrm{Na}_{2} \mathrm{SO}_{4}$. It is possible to see, besides the control cell in the region of $430 \mathrm{mV} \lesssim N E P \lesssim 500$ $m V$ and $6 \lesssim p H \lesssim 6.4$, another region for different plasma generation conditions for which $150 \mathrm{mV} \lesssim N E P \lesssim 350 \mathrm{mV}$ and $5.8 \lesssim p H \lesssim 6.4$, and finally, for bidistilled water, it was found the region $0 m V \lesssim N E P \lesssim 180 m V$ and $5.5 \lesssim p H \lesssim 6.0$. Please note the case for which $N E P \approx 100 \mathrm{mV}$ in the interval $5.5 \lesssim p H \lesssim 6.0$. This corresponds to $\mathrm{Cu}$ dissolving in water, keeping the $N E P$ constant increasing the $p H$ instead.

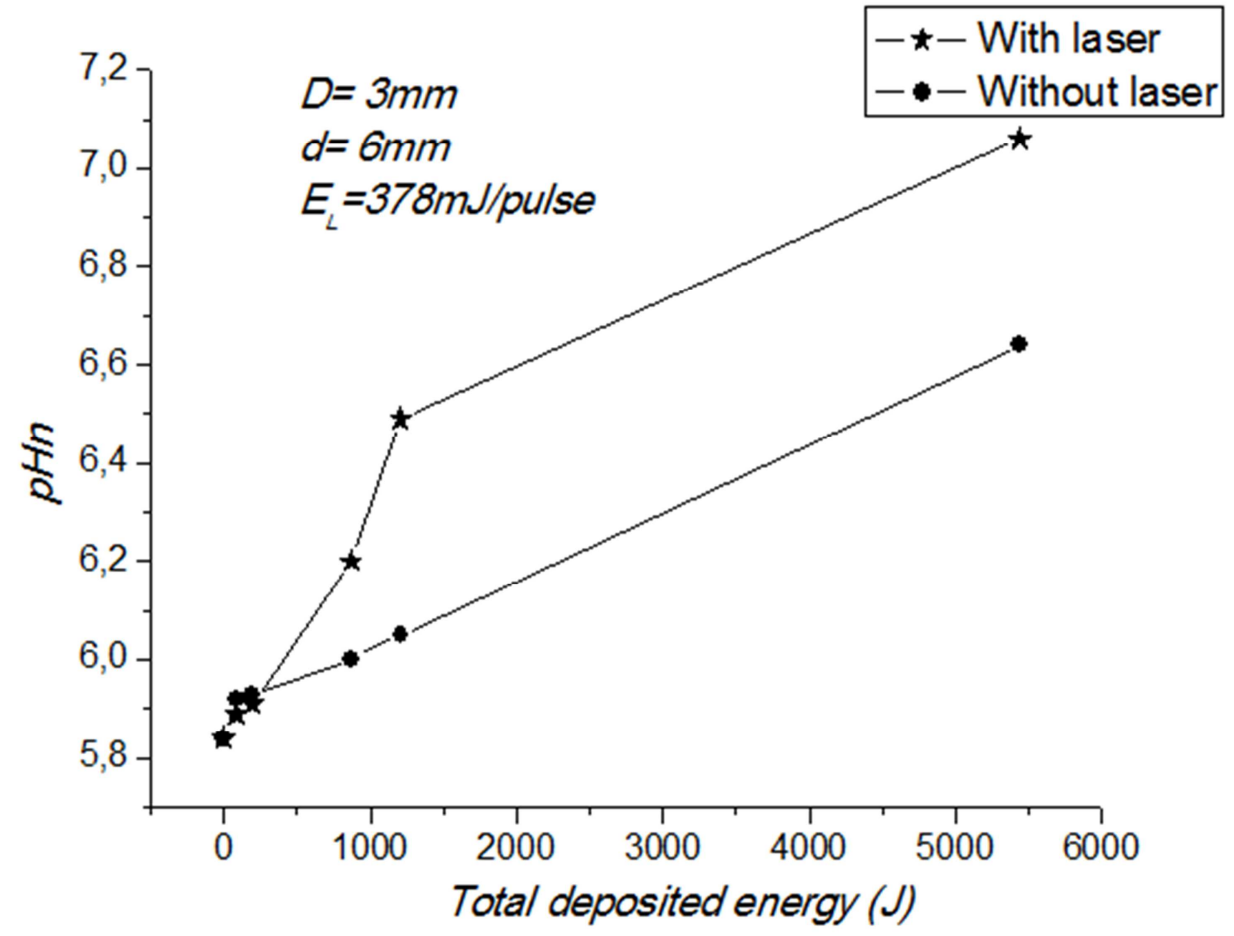

(a)

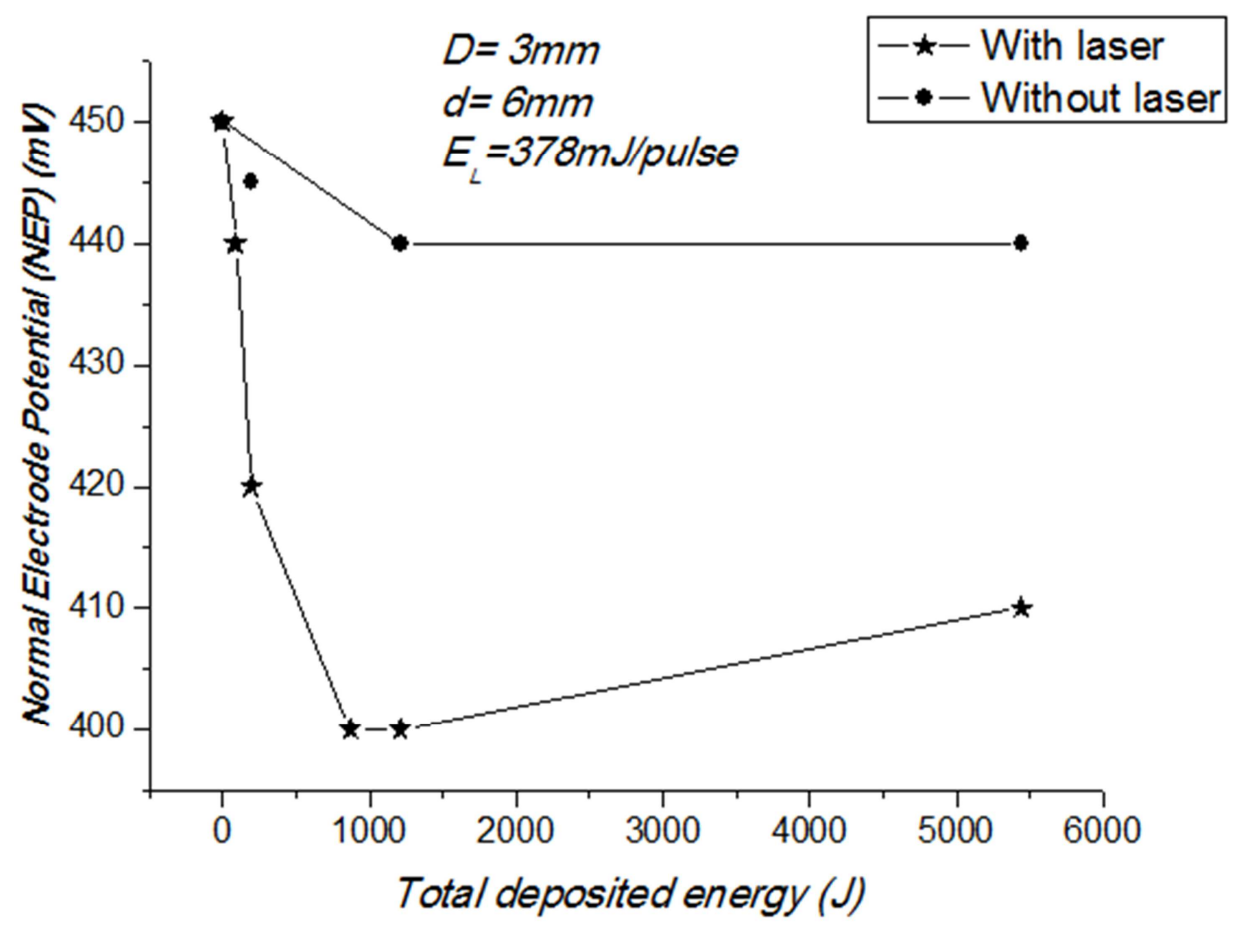

(b) 


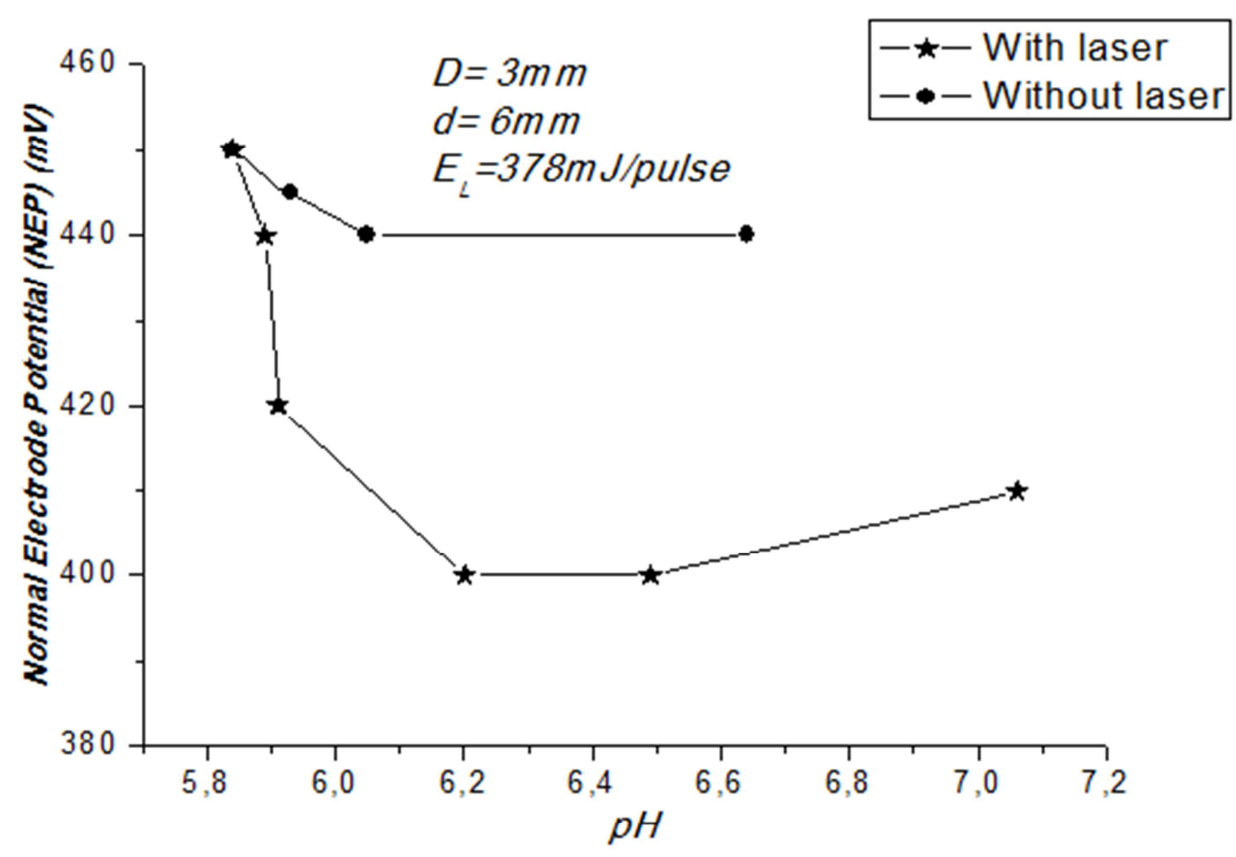

(c)

Figure 14. (a) pH versus total deposited energy in control cell and the irradiated covered cells. Diluted Sodium sulfate solution. Laser pulse energy is $378 \mathrm{~mJ} /$ pulse.(b) The normal electrode potential (NEP) versus the total deposited energy.(c) The normal electrode potential (NEP) versus $\mathrm{pH}$.

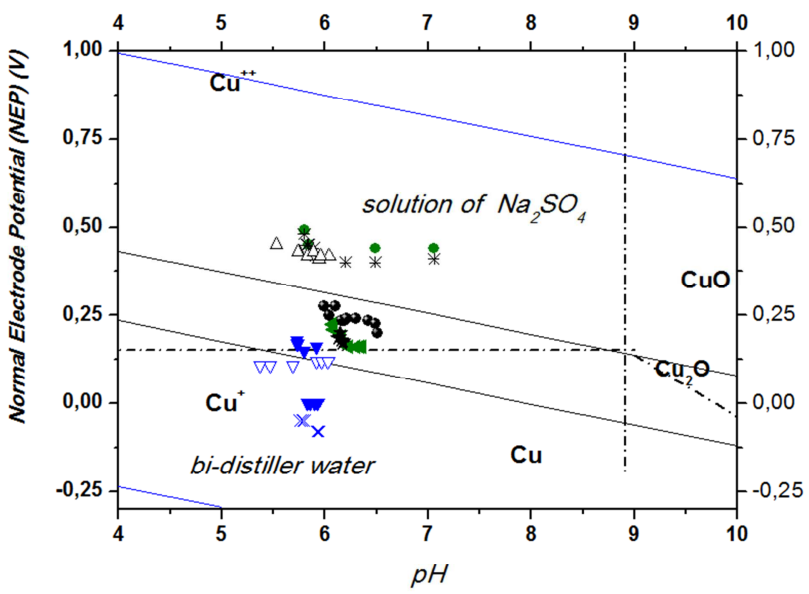

(a)

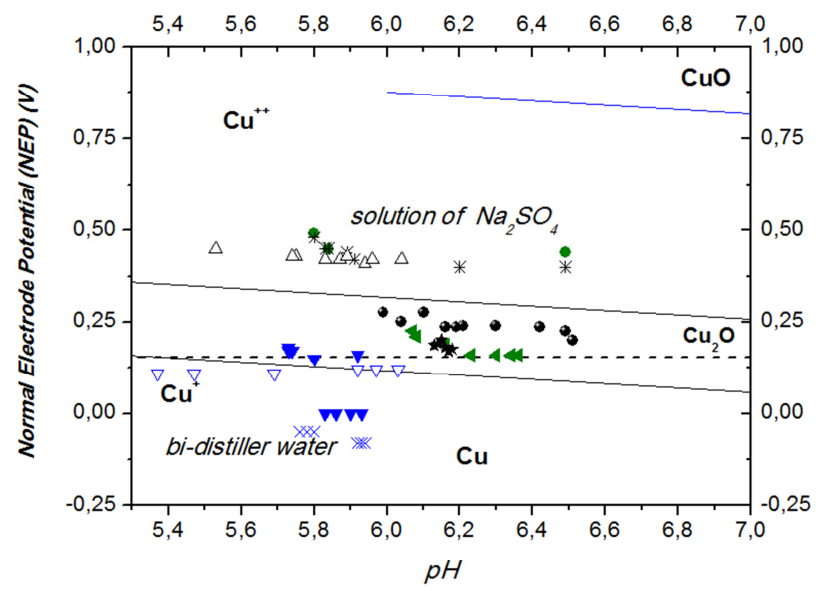

(b)

Figure 15. (a) The Pourbaix diagram for several D values in aqueous solutions for control cells and irradiated cells. Comparison between bi-distilled water and diluted $\mathrm{Na}_{2} \mathrm{SO}_{4}$ solution. (b) Enlargement of (a) $\nabla$ Bi distiller water $D=1 \mathrm{~mm}, \boldsymbol{x}$ Bi distiller water, $\nabla$ Bi distiller water $D=5 \mathrm{~mm}$, $\bullet$ Control cell $D=3 \mathrm{~mm}$, $\checkmark \mathrm{Na}_{2} \mathrm{SO}_{4} \mathrm{D}=1 \mathrm{~mm}$, $\star \mathrm{Na}_{2} \mathrm{SO}_{4} \mathrm{D}=1 \mathrm{~mm}, \triangle \mathrm{Na}_{2} \mathrm{SO}_{4} \mathrm{D}=2 \mathrm{~mm}$, * $\mathrm{Na}_{2} \mathrm{SO}_{4} \mathrm{D}=3 \mathrm{~mm}, \boldsymbol{O} \mathrm{Na}_{2} \mathrm{SO}_{4} \mathrm{D}=5 \mathrm{~mm}$.

\subsection{Cu in the Solution}

Finally, another aspect of this subject was analyzed, which is the dilution of the $C u$ from the immersed plates in the cases of electrolytic aqueous solutions, both for bidistilled water and the solution of $\mathrm{Na}_{2} \mathrm{SO}_{4}$ in the twin cells described above. The aqueous solutions were also analyzed for possible $\mathrm{Cu}$ contamination. The spectra were used in all the experiments as the spectra base.

The aim of experiments are the inspection of $\mathrm{Cu}$ dissolved in electrolyte by two methods, namely, by the spectrophotometer and by Laser Induced Breakdown
Spectroscopy (LIBS).

In Figures 16a it is summarized the results of the difference between the measured contents of $\mathrm{Cu}$ between the twin cells when the electrolyte was a $\mathrm{Na}_{2} \mathrm{SO}_{4}$ aqueous solution.

In Figure 16b, represents the difference between the obtained spectra from the irradiated cell minus the control cell spectra. The principal observed peak in the spectra in both cases lies where the absorption $C u$ band is expected.

Using the LIBS method, the results brought the data presented in Figure $17 \mathrm{a}$ and $17 \mathrm{~b}$. In these figures, each point $\star$ represents the $\mathrm{Cu}$ content in ppm found in the irradiated solution after the completion experience obtained by LIBS. 
Similarly, each point $\bullet$ corresponds to the $\mathrm{Cu}$ concentration found in solution in the non-irradiated cell. Figure 17a, plots the copper concentration versus the distance from the formed plasma to the $\mathrm{Cu}$ surface, $\mathrm{D}$. At each point the experience

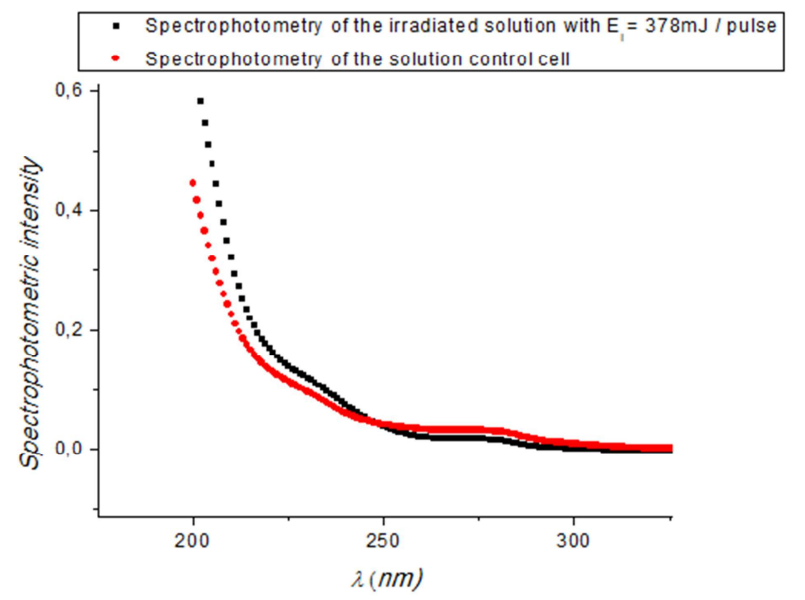

(a)

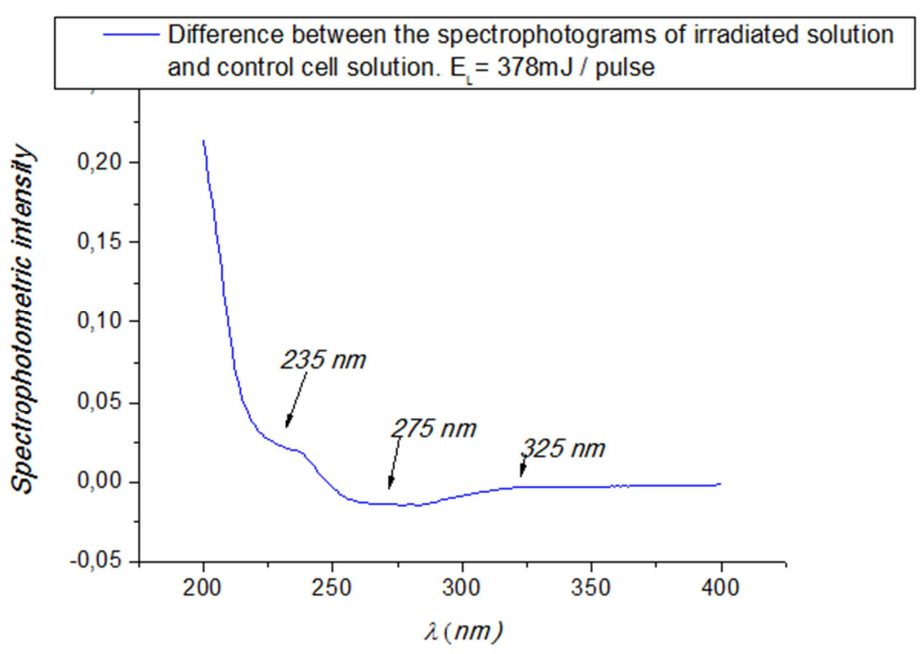

(b)

Figure 16. (a) Spectrophotometry of the irradiated solution and the control cell solution. $E L=378 \mathrm{~mJ} /$ pulse (b) Difference between the spectrophotograms of irradiated solution and control cell solution. $E L=378 \mathrm{~mJ} /$ pulse.

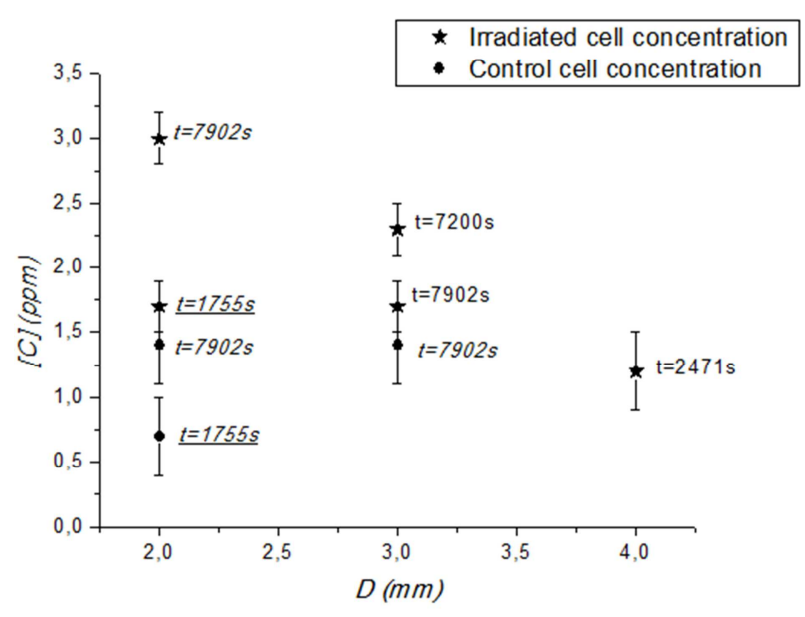

(a)

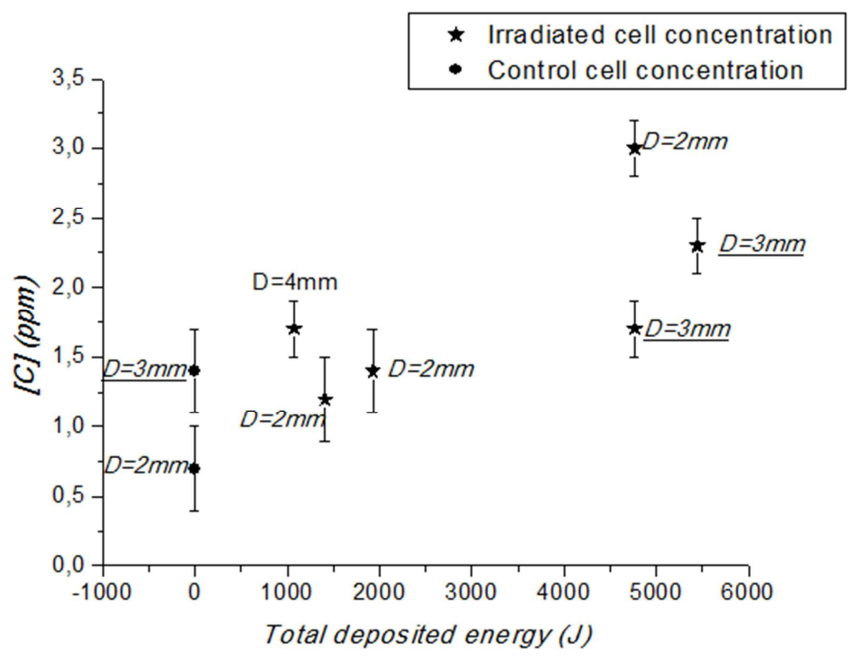

(b)

Figure 17. Cu concentration in remaining solution, obtained by LIBS technique.

\subsection{Cell with Two Cu Plates}

It was deal here with cases when the $C u$ plates were not connected to an external battery, since all the results when there is a current fed by an external source had been published already [4, 5], so these results shall be cited whenever it will be necessary. One point to add is that the galvanic pulse observed in this case, had the unusual property to switch from negative to positive but the reason for this was uncertain. It is described here what is to our knowledge, the main feature that makes this change possible.

The cases of two immersed electrodes with no connected batteries are qualitatively similar to the one with only one piece.
It was proved that the galvanic pulse generated in the irradiated cell, is different when taken from one or from other solid piece in a particular cell. This has consequences on the pulse measured in the sense that, in certain conditions, some pulses can become from negative to positive or vice versa. This is because $\mathrm{Cu}$ pieces have different NEP values when they are submerged.

What is new about this situation is that the Pourbaix diagram has differences with the one for only one piece of $\mathrm{Cu}$. Regarding to plasma generated within a liquid bulk, the information reported is poor $[15,16]$. We have not found studies in electrical conduction in liquid bulk when a plasma is generated by the laser irradiation in the literature. 


\section{Conclusions}

As a general conclusion, the laser irradiation increases the temperature and change the $\mathrm{pH}$ of the solution, resulting it more basic. An increase in the $\mathrm{T}$ and $\mathrm{pH}$ of an irradiated cell were observed, while for a twin cell, otherwise identical to the former but not irradiated, these parameters remains constant or slowly decrease. Comparing data from uncovered and covered cells, it is possible to be certain that the $\mathrm{CO}_{2}$ dilution is responsible for a slight drop in the $p H . \Delta p H$ is dependent on the laser energy per pulse, and it also depends on the solution pureness.

It was also measured a change in the ORP of a metallic surface immersed in an aqueous solution. These changes bring information on the oxidation state of the metal surface. ORP measurements shows that by laser action, the medium becomes more reductant.

Galvanic pulse intensity is proportional to the solution impurity and the laser energy per pulse. This indicates more charge carriers in solution. It is also dependent nonlinearly with the distance $\mathrm{D}$ between the plasma and $\mathrm{Cu}$ surface.

A great $\triangle p H$ implicates a higher pulse intensity.

There is evidence that the $C u$ present in the electrolyte is dependent on the produced laser plasma. $\mathrm{Cu}$ plate dissolves by corrosion, but higher concentration of $\mathrm{Cu}$ were found in the residual solution of laser exposed cell, than in the cell control. The found concentration depends on the total deposited energy and the distance D.

All these results are possible when laser action generates a plasma in the liquid medium and a simultaneous galvanic pulse.

The results presented in $[5,6]$ for cells with 2 electrodes, also with the results presented here lead to explain the disturbed transition region by the laser between metal and liquid. The ionized matter produced by the plasma increase the rate of ion production acting as a virtual electrode, changing the properties of the electrolyte, thus changing the rate of hydrogen production.

\section{References}

[1] C. A. Sacchi, "Laser-induced electric breakdown in water". J. Opt. Soc. Am., B 8, 337345 (1991).

[2] G. Bertuccelli, H. O. Di Rocco, D. Iriarte, H. F. Ranea Sandoval and M. Romeo y Bidegain, "Radiative mechanisms in laser produced plasmas in Xe". Journal of Quantitative Spectroscopy and Radiative Transfer, 61, 309317 (1999).

[3] Bertuccelli, G., Di Rocco, H. O., Ranea-Sandoval, H. F, "Temperature and electron density gradient in Xe laser produced plasmas, by spectral analysis". Journal of Quantitative Spectroscopy and Radiative Transfer, 65, 645 $653(2000)$.
[4] D. Dertuccelli and H. F. Ranea-Sandoval, "Perturbations of Conduction in Liquids by Pulsed Laser Generated Plasma". IEEE Journal of Quantum Electronics, JQE-37, 856861 (2001).

[5] Espejo, V., Bertuccelli, D., Ranea-Sandoval, H. F., "LaserInduced Plasma in Liquid Conduction Cell: Alterations in Current-to-Voltage Characteristics". IEEE Transactions on Plasma Science, 38, 8691 (2010).

[6] D. Bertuccelli, H. F. Ranea-Sandoval, and V. Espejo, "Laser Plasma Generation in Liquids. Possible Perturbations of the Boundary Layer Dynamics in a Metallic Surface in a Cell Filled With Conducting Liquid". IEEE Transactions on Plasma Science, 39, 16311634 (2011).

[7] Delahay, P., Pourbaix, M. and Van Rysselberghe, P. J., "Potential-pH diagrams". Journal of Chemical Education, 27, 685 (1950).

[8] Pourbaix, M. "Atlas of electrochemical equilibria in aqueous solution" (English translation by James Franklin). Pergamon Press, 1966.

[9] Flávia P. C. Silvas, Mónica M. Jiménez Correa, Marcos P. K. Caldas, Viviane T. de Moraes, Denise C. R. Espinosa, Jorge A. $S$. Tenório "Printed circuit board recycling: Physical processing and copper extraction by selective leaching" Waste Management, Vol 46, 2015, Pages 503-510.

[10] P. W. Atkins, "PHYSICAL CHEMISTRY, Atkins- Sixth Edition. Oxford University Press.(1998).

[11] J. O' M. Bockris and A. K. N. Reddy, "Electroquímica Moderna”. Editorial Reverte, España, 1979.

[12] JO Zerbino LM Gassa "Electrochemical impedance spectroscopy study of cuprous oxide films formed on copper: Effect of $\mathrm{pH}$ and sulfate and carbonate ions" Feb 2003 Journal of Solid State Electrochemistry.

[13] M. Shahid, N. Bt Bidin, A. Rehman, "Enhancement of Hydrogen by laser focusing during plasma electrolysis of wáter" Optoelectronics And Advanced Materials - Rapid Communications Vol. 4, No. 11, 2010, P. 1670-1675.

[14] M. Shahid, N. Bidin, Y. Mat Daud, M. Talha, M. Inayat ullah "Anomalous Hydrogen Production during Photolysis of $\mathrm{NaHCO}_{3}$ Mixed Water". International Journal of Scientific \& Engineering Research Volume 2, Issue 4, April-2011.

[15] C. Miron, M. A. Bratescu, N. Saito, O. Takai "Effect of the electrode work function on the water plasma breakdown voltage" Current Applied Physics 11 (2011) S 154-S 158.

[16] N. V. Tarasenko, A. V. Butsen "Laser synthesis and modiécation of composite nanoparticles in liquids" Quantum Electronics 40 (11) 986-1003 (2010).

[17] Muhammad Shahid, Norih Bidin, Yacoob Mat Daud, M. Inayat Ullah "Chronological characteristics of laser spark emission spectra in water". Journal Of Intense Pulsed Lasers And Applications In Advanced Physics Vol. 2, No. 1, p. 5-9, 2012. 


\section{Biography}

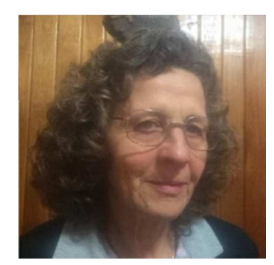

Daniela Bertuccelli graduated from the Facultad de Ciencias Exactas de la Universidad Nacional del Centro de la Provincia de Buenos Aires (Argentina) in 1980; she received her Ph. D. degree Physics in 1985 from Universidad Nacional de La Plata (Argentina). She is currently Professor at the Facultad de Ciencias Exactas de la Universidad Nacional del Centro de la Provincia de Buenos Aires, Argentina. Since 1985 she is a Member of the Spectroscopic Laboratory at the Instituto de Física "Arroyo Seco" (IFAS). Her present research interests include Molecular and Atomic Spectroscopy and Laser Induced Breakdown Spectroscopy (LIBS).

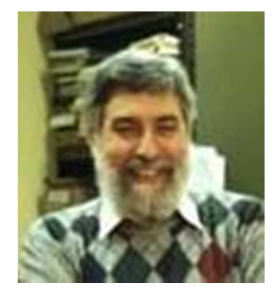

Héctor F. Ranea Sandoval received his Licenciado en Física (Ms. Sc.) degree from the Universidad Nacional de La Plata (Argentina) in 1973; he received his Ph. D. in 1977. His research was primarily in Laser Physics and Photophysics. He was visiting scientist at the Department of Physics of the Universidad Estadual de Campinas (Brasil), Laboratorio di Elettronica Quantistica, Firenze (Italy), Laser and Plasma Laboratory at the College of Engineering of Colorado State University, Photonics Group of the Departamento de Física of Universitat de les lles Balears (Spain). Was Responsible of the IFAS Quantum Electronics Laboratory, he is Independent Scientist of CONICET (Argentina). 